\title{
Influence of the test situation on pup retrieval behavior of normal and undernourished lactating rats
}

J.B.T. Rocha,

F.A.A. Soares and C.F. de Mello
Departamento de Química, Centro de Ciências Naturais e Exatas, Universidade Federal de Santa M aria, Santa Maria, RS, Brasil

\section{Correspondence}

\section{J.B.T. Rocha}

Departamento de Q uímica

Centro de Ciências Naturais e

Exatas, UFSM

97105-900 Santa M aria, RS

Brasil

Fax: + 55-55-220-8031

E-mail: jbtrocha@base.ufsm.br

Research supported by FAPERGS

(No. 92) to J.B.T. Rocha.

J.B.T. Rocha and C.F. de Mello

are recipients of $\mathrm{CNPq}$ fellowships.

Received September 11, 2000 Accepted October 15, 2001

\section{Abstract}

Undernutrition of dams and pups disrupts the retrieval efficiency of mothers. However, if the mothers are assessed in their home cages, they spend more time with their litters. In the present study the effect of test conditions on pup retrieval behavior of mothers receiving a $25 \%$ (well-nourished group) and $8 \%$ casein diet (undernourished group) was examined. In agreement with previous studies, undernourished mothers spent more time with their litters than well-nourished dams as lactation proceeded. Pup retrieval behavior varied with test conditions. In the first experiment, the maternal behavior of dams was assessed by the standard procedure (pups were separated from their mother and scattered over the floor of the home cage). The mother was then returned and the number of retrieved pups was recorded. From day 3 to 8 , the retrieval efficiency of undernourished dams decreased, while the retrieval efficiency of well-nourished mothers did not vary. In the second experiment, mothers were subjected to a single retrieval test (on day 9 of lactation) using the procedure described for experiment 1 . No difference between well-nourished and undernourished mothers was observed. In the third experiment, seven-day-old pups were separated from the mothers and returned individually to a clean home cage. Dietary treatment did not affect the retrieval efficiency. However, undernourished dams reconstructed the nest more slowly than did well-nourished dams. Taken together, these results suggest that pup retrieval behavior of the undernourished mother is not impaired by dietary restriction when the maternal environment is disturbed minimally.

\section{Introduction}

Perinatal undernutrition may change different anatomical, neurochemical, physiological, pharmacological, developmental and behavioral parameters (1-7). The methods used to produce undernutrition in rats are accompanied by changes in mother-pup interaction (8-12) and it has been proposed
Key words - Retrieval

- Undernourishment

- Pup behavior

- Lactating rats 
tions $(11,12,18,19)$ as well as using a more natural approach by observing dam behavior in the home cage without disturbing the ongoing maternal behavior $(4,11,12,17,20)$. Most of the studies which evaluate the pup retrieval behavior of undernourished dams (caused by food restriction or by feeding dams a low protein diet) showed a decrease in the efficiency of pup retrieval behavior as a function of days of testing $(11,12,19,21$ 23). In a more detailed second study, Wiener et al. (12) reported that dams maintained on a low protein diet retrieved less than wellnourished dams after some retrieval tests, but during periods not associated with the tests, malnourished dams spent more time with their pups. Several other literature reports demonstrated that malnourished dams spend more time with litters when observations are made in the home cage with little disturbance of dam behavior $(4,12,13,17,20)$.

Taken together, these results suggest that under disturbed conditions malnourished mothers present a deficit in some pup-oriented behaviors, mainly in retrieval. On the other hand, under undisturbed conditions malnourished dams seem to present more pup-oriented behaviors than well-nourished mothers.

Pup retrieval behavior of undernourished dams has been studied by some standard procedures: the litter is separated from the dam and then returned to the side opposite to the nest and the pups are usually scattered over the floor of the cage. This situation seems to rarely occur in an undisturbed maternity environment, and may represent a stressful situation to dams. Undernourished dams may be more susceptible to these changes due to their nutritional condition $(18,19)$. In the present study, pup retrieval behavior of dams maintained on a low protein diet was examined by the standard procedure used in the literature and also using three additional procedures: 1) retrieval behavior was assessed by the standard literature procedure except that dams were sub- jected to a single retrieval test on day 9 after delivery; 2) after removing the entire litter from the home cage, retrieval behavior was assessed by sequentially adding pups oneby-one to the side opposite to the nest, and 3) on day 10 after delivery, a single pup was gently removed from the nest and immediately returned to the side opposite to the nest. The last two procedures differed from the standard procedure of the literature and aimed to minimize the test-induced changes in the nest environment in order to clarify whether the previously reported deficit in pup retrieval behavior of undernourished dams could be attributed to the test situation.

\section{Material and Methods}

\section{General procedures and subjects}

Wistar rats (Rattus norvegicus) from our own breeding stock were maintained on a 12-h light/12-h dark cycle (lights on at 6:00 h) with free access to laboratory chow containing $20 \mathrm{~g} \%$ protein and water. The breeding regimen consisted of grouping three virgin females (90-120 days of age) and one male for 20 days. Pregnant rats were then selected and placed in individual cages. Wood shavings were provided as nesting material.

On the day of birth (day 1), litters were culled to eight (4 males and 4 females) and dams assigned at random to a 25 or $8 \%$ casein diet (for details about the diets see Ref. 24). Dams and pups were weighed on days 0,7 and 14 .

\section{Experiment 1}

O bservation of dam behavior in the home cage

Dam behavior was assessed from day 5 to 14 between 13:00 and 13:30 h. Observations of dam behavior were recorded over a 30-min period using 10 spot checks at 3-min intervals. Each observation was instantaneous and a note was made whether dams were in 
or out of the nest (a dam was considered to be in the nest only if she was engaged in nursing). Data were analyzed using a 2 (diets) x 10 (observations) design with the last factor treated as repeated measure.

Pup retrieval behavior using the standard literature procedure

Retrieval behavior was assessed from day 3 to day 8 after delivery. The dams were tested for pup retrieval behavior between 15:00 and 17:00 h. The home cage was moved from the colony room to an adjacent anteroom and the dam was then separated from the litter for $3 \mathrm{~min}$. The dam was kept in a holding cage, and the pups were kept in a plastic container. The pups were returned to the home cage and scattered over the floor of the cage opposite to the nest. The dam was returned to the nest and the number of retrieved pups was recorded. The test continued until the entire litter was retrieved or until $7 \mathrm{~min}$ had elapsed. Data were analyzed using a 2 (diets) x 6 (days of testing) design with the day factor treated as repeated measure.

\section{Experiment 2}

Pup retrieval behavior using a single test

Retrieval behavior was assessed as described for Experiment 1 (pup retrieval behavior using the standard literature procedure) except that the dams used in this experiment were subjected to a single retrieval test on day 9 after delivery. Data were analyzed by one-way ANOVA considering diets as fixed treatments.

\section{Experiment 3}

O bservation of dam behavior in the home cage

Dam behavior was assessed as described in Experiment 1.
Individual pup retrieval and nest building behavior

On day 7 after delivery, the home cage was moved from the colony room to an adjacent anteroom, where the pups were separated from the dam and kept in a plastic container. Each pup was weighed and sequentially positioned one-by-one in the cage on the side opposite to the nest, regardless of dam position. The latency to retrieval of each pup, presented individually, was recorded. If the mother had not retrieved within $120 \mathrm{~s}$, the pup was returned to the nest by the experimenter and the next pup was immediately positioned in the cage on the side opposite to the nest, regardless of dam position. The retrieval test was carried out between 15:00 and 17:00 h. Data were analyzed by 2 (diets) $\times 7$ (order of pup presentation) ANOVA with the pup factor treated as repeated measure. In order to meet the assumption of homogeneity of variances, data were transformed by taking their square root before statistical analysis.

The nest building behavior of dams was assessed just after the individual retrieval test. Dams and litters were moved to a clean cage. The cage was then returned to the colony room and the nest condition was observed at 30-min intervals for $2 \mathrm{~h}$. A dam was recorded as having a nest if the wood shavings were arranged in a circular or semicircular mode around the litter or when the litter was covered with nesting material.

"Little disturbed retrieval test"

On day 10 after delivery, the home cage was removed from the colony room to an adjacent anteroom. After transportation of the cage, a short period of time (5 to $10 \mathrm{~min}$ ) was given to the mother to readapt to the new position of the cage. The dam was then gently moved to one side of the nest and one pup was selected at random and placed on the side opposite to the nest. The latency to 
retrieve this single pup was recorded. If the dam had not retrieved within $180 \mathrm{~s}$ the test was ended. The retrieval test was carried out between 14:30 and 15:00 h.

\section{Results}

\section{Body weight of dams and pups}

Since the body weight of dams and pups from Experiments 1, 2 and 3 were similar, they were pooled in the statistical analysis. In the case of dams, the main effects (diet and day) were significant but since the day $\mathrm{x}$ day interaction was also significant they will not be discussed $(\mathrm{F}(2,118)=52.77, \mathrm{P}<0.01)$. The body weight of well-nourished dams increased as a function of days, while the body weight of undernourished dams decreased (Table 1). Analysis of pup body weight revealed a significant diet $x$ day interaction $(\mathrm{F}(2,118)=401.90, \mathrm{P}<0.01)$. The body

Table 1. Effects of a low protein diet on body weight (g) of dams and pups.

\begin{tabular}{|c|c|c|c|c|}
\hline \multirow[t]{3}{*}{ Days after delivery } & \multicolumn{4}{|c|}{ Casein diet group } \\
\hline & \multicolumn{2}{|c|}{$25 \%$} & \multicolumn{2}{|c|}{$8 \%$} \\
\hline & Dam & Litter & Dam & Litter \\
\hline 0 & $214.1 \pm 2.05$ & $5.21 \pm 0.04$ & $215.1 \pm 1.79$ & $5.43 \pm 0.02$ \\
\hline 7 & $228.4 \pm 2.18$ & $19.1 \pm 0.18$ & $207.6 \pm 1.57^{*}$ & $12.1 \pm 0.14^{*}$ \\
\hline 14 & $232.1 \pm 1.60$ & $33.7 \pm 0.37$ & $198.7 \pm 1.85^{*}$ & $19.4 \pm 0.20 *$ \\
\hline
\end{tabular}

Data are reported as means \pm SEM for 70 dams and litters (22 from Experiment 1, 20 from Experiment 2 and 28 from Experiment 3). ${ }^{*} P<0.01$ compared to the wellnourished group (one-way ANOVA).

Figure 1. Effect of a low protein diet on time spent nursing by well-nourished dams $(25 \%$ casein diet group; circles) and undernourished dams (8\% casein diet group; triangles). Data are reported as means \pm SEM. The sample size for each dietary condition was 11 dams and litters. $* \mathrm{P}<0.01$ compared to well-nourished dams (one-way ANOVA).

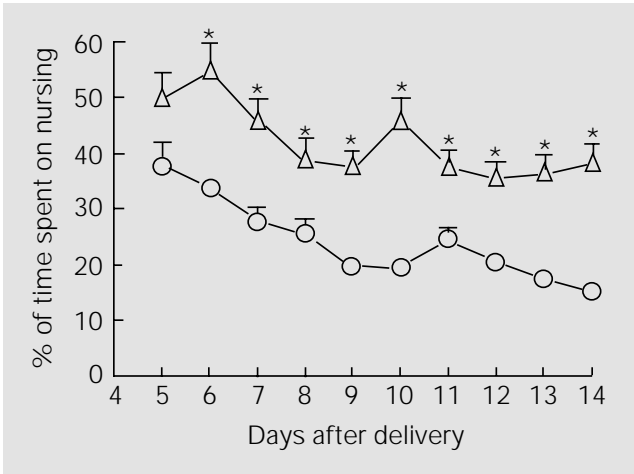

weight of pups from both dietary treatments increased significantly from birth to day 14 , but the increase was considerably less for rats raised by dams maintained on the low protein diet (Table 1).

\section{Observation of dam behavior in the home cage}

Since the undisturbed behavior of dams in Experiments 1 and 2 was similar, the animals were analyzed and presented together to avoid redundant data presentation. The analysis revealed only a significant main effect of diet $(F(1,48)=41.83, \mathrm{P}<0.01)$ due to more time spent nursing by dams raising undernourished animals (41.4\%) compared to well-nourished dams (24.6\%) (Figure 1). Analysis revealed a nonsignificant effect of days $(\mathrm{F}(9,432)=1.69, \mathrm{P}<0.10)$ and a significant diet $x$ day interaction $(F(9,432)=1.82$, $\mathrm{P}<0.10)$ since well-nourished dams showed a visible decrease in time spent nursing as lactation proceeded, while undernourished dams did not exhibit a consistent decrease in the time spent on this behavior.

\section{Experiment 1}

Retrieval behavior determined by using the standard literature procedure

Analysis of pup retrieval behavior of dams subjected to six consecutive tests from day 3 to 8 revealed a significant diet $x$ day interaction $(\mathrm{F}(5,110)=3.97, \mathrm{P}<0.01)$ due to the striking decrease in the retrieval efficiency of undernourished dams when compared to well-nourished dams. From day 6 to 8 , dams maintained on the $8 \%$ diet retrieved their pups less than well-nourished rats (Figure 2).

\section{Experiment 2}

Analysis of pup retrieval behavior of dams subjected to six consecutive tests from day 3 to 8 demonstrated that the retrieval effi- 
ciency of dams maintained on a low protein diet decreased as a function of testing days. To assess whether this was simply a consequence of time on the low protein diet, a single retrieval test was carried out on 10 well-nourished and 10 undernourished dams at day 9 after the beginning of dietary treatment. ANOVA revealed no significant effect of diet $(F(1,18)=1.84, P>0.10)$. The percentage of retrieved pups was $51.3 \pm 8.6$ and $42.4 \pm 12.2$ for the well-nourished and undernourished groups, respectively (data are reported as mean $\pm \mathrm{SD}$ ).

\section{Experiment 3}

Individual retrieval

Analysis of the retrieval test carried out on day 7 after delivery (individual retrieval) revealed no significant main or interaction effects. The latency to retrieve each pup was similar in both dietary groups and the order of pup presentation did not affect significantly the latency to retrieve the pups (Figure 3). The proportion of pups that were not retrieved within $120 \mathrm{~s}$ did not differ between dietary groups (5 pups from two litters were not retrieved in the normal group and only one pup was not retrieved in the undernourished group; $\mathrm{P}>0.10$, two-tailed Fisher test, data not shown).

Nest building

The nest building behavior of dams recorded on day 7 after delivery revealed that undernourished dams reconstructed the nest more slowly $(62.1 \pm 1.7$ min, mean \pm SEM) than control dams $(34.3 \pm 0.7 \mathrm{~min})(\mathrm{F}(1,26)$ $=14.74, \mathrm{P}<0.01)$.

\section{"Little disturbed retrieval test"}

Statistical analysis of the data from the retrieval test carried out on day 10 revealed no significant effect of dietary treatment on the latency of dams to retrieve the single pup taken away from the nest, which was $82.7 \pm 4.6 \mathrm{~s}$ (mean \pm SEM) for the $25 \%$ group and $58.4 \pm$ $4.1 \mathrm{~s}$ for the $8 \%$ group $(\mathrm{F}(1,26)=1.19, \mathrm{P}>0.10)$. The number of dams that did not retrieve within $180 \mathrm{~s}$ did not differ between nutritional groups (3 dams in the well-nourished group and 2 in the undernourished group did not retrieve; $\mathrm{P}>0.10$, two-tailed Fisher test).

\section{Discussion}

Dams maintained on a low protein diet under undisturbed conditions spent more time nursing than dams maintained on a normal diet (Figure 1), as also reported by other laboratories $(4,9,12,17)$. The extra time spent in the nest by dams raising undernourished pups is probably related to the physical and behavioral characteristics of deprived suckling. It has been suggested that time spent in the nest by dams is mainly regulated by heat production by the dam as she crouches over the pups (25). In addition, as cited by Stern and Lonstein (26), the heat flow between

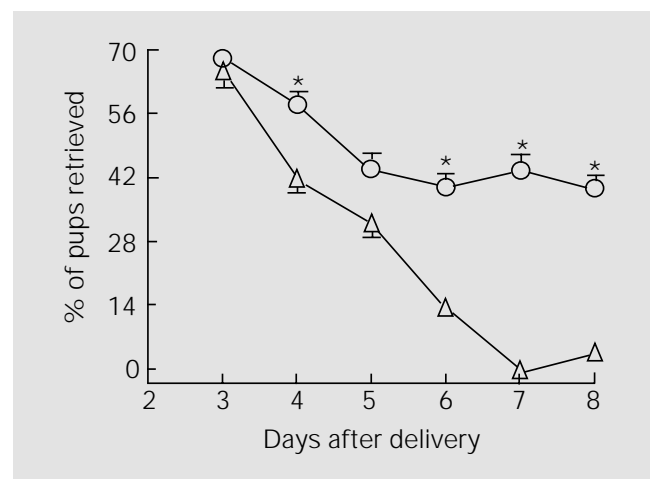

Figure 2. Retrieval behavior of well-nourished $(25 \%$ casein diet group; circles) and undernourished dams (8\% casein diet group; triangles). Data are reported as means \pm SEM. The sample size for each dietary condition was 10 dams and litters. $* \mathrm{P}<0.01$ compared to undernourished dams (one-way ANOVA).

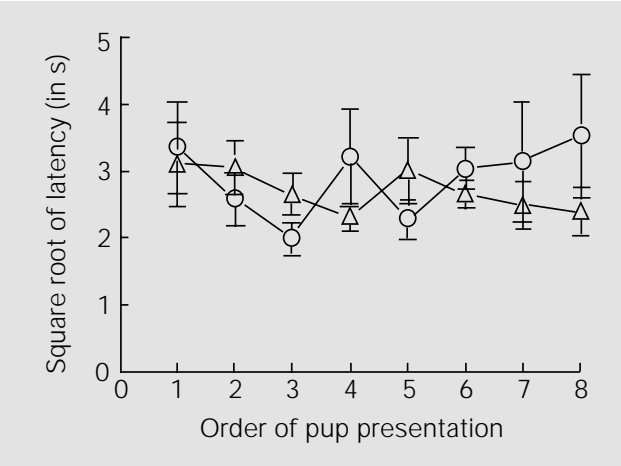

Figure 3. Latency to retrieve pups presented individually to dams on day 7 after delivery. Well-nourished dams (25\% casein diet group; circles) and undiet group; triangles). Data are reported as means \pm SEM. The sample size for each group was 14 dams and litters. dernourished dams (8\% casein 
dam and litter occurs only from the dam to the pups and not vice versa, as proposed by Leon et al. (25). Consequently the extra time spent by undernourished mothers with pups is probably related to a heightened motivation of the undernourished pups to suckle, which elicits more efficiently the nursing behavior of their dams. In fact, malnourished pups spend more time suckling compared to well-nourished pups (20).

Pup retrieval behavior is regulated by multisensory processes and can be considered as a chain of motor responses elicited by a variety of stimuli emanating from the female and/or pups which promotes orientation, attention and arousal (27). The initial stimuli induce proximity of dam and pups and perioral trigeminal stimulation elicits the retrieval and grouping of the pups in the nest $(28,29)$. A variety of factors can affect pup retrieval behavior, including pharmacological and environmental manipulation of mothers or pups $(11,12,18,19,30-34)$.

The retrieval ability of undernourished dams deteriorates with consecutive testing, and this finding seems to be at variance with data acquired by observing undisturbed maternal behavior. The results of the present study using the standard procedure of the literature are in good agreement with previously published data $(11-13,19,23)$. The altered behavior of undernourished dams has been interpreted by some investigators as a result of competition among mutually exclusive behaviors (e.g., food-related behaviors versus puporiented behavior) for dams receiving about $50 \%$ of the food eaten by normal dams $(11,18)$. Dams maintained on a low protein diet eat less than normal dams, as can be inferred from the loss in body weight of undernourished rats (Table 1). This may aggravate the nutritional status of dams maintained on a low protein diet, which may contribute to disturbing the maternal behavior under repetitive testing situations. Our results suggest that these repetitive tests are necessary to alter the retrieval behavior of undernourished dams. Wiener et al. (35) showed that the maternal pituitary-adrenal responsiveness toward malnourished pups decreases as lactation proceeds, coinciding with the retrieval deficits observed in undernourished dams (12). Furthermore, Wiener et al. (35) demonstrated that the responsiveness of well-nourished dams to well-nourished pups was higher than the responsiveness to malnourished pups, indicating that undernourished pups elicit less maternal responsiveness than well-fed pups. The decrease in retrieving efficiency probably results from an interaction between nutritional state of mother and pups and test conditions, since it was demonstrated that the retrieval behavior of dams caring for pups who were fed only $8 \mathrm{~h}$ daily is not negatively affected by repetitive testing (14). Further support for the deleterious influence of repetitive testing on retrieval behavior of undernourished mothers was obtained in this study: on day 10, undernourished dams retrieved with similar efficiency to well-nourished dams, when the home cage environment was left undisturbed.

In contrast, under undisturbed situations undernourished dams seem to exhibit adequate maternal behavior since they spend more time in the nest with the entire litter $(4,17,20)$. If undernourished dams exhibited inadequate retrieval behavior it would be expected to encounter pups out of the nest more frequently in litters raised by undernourished dams. Nevertheless, this does not seem to be the case $(9,17$, and Rocha JBT and Mello CF, unpublished observations).

Our data suggest that undernourished dams present deficits in pup-oriented behavior only when they are subjected to disturbed situations, such as repetitive testing (Figure 2) $(11,12,19)$ and/or to changes in the home cage environment.

\section{Acknowledgments}

The authors would like to thank D. Vendite and F.T. Rotta for helping with some of the experiments. 


\section{References}

1. Mello CF, Rocha J BT, Huang $\mathrm{Cl} \&$ Dias RD (1992). Undernutrition during suckling has no effect on the rat locomotor activity response to caffeine. Brazilian J ournal of Medical and Biological Research, 25: 187191.

2. Ximenes-da-Silva A \& Guedes RCA (1991). Differential effect of changes in blood glucose levels on the velocity of propagation of cortical spreading depression in normal and malnourished rats. Brazilian J oumal of Medical and Biological Research, 24: 1277-1281.

3. Guedes RCA, Andrade AFD \& Cabral-Filho J E (1987). Propagation of cortical spreading depression in malnourished rats: facilitatory effect of dietary protein deficiency. Brazilian J ournal of Medical and Biological Research, 20: 639-642.

4. Rocha J BT \& Vendite D (1990). Effects of undernutrition and handling during suckling on shuttle avoidance and footshock escape behavior and on plasma glucose levels of young rats. Developmental Psychobiology, 23: 157-168.

5. Almeida SS, Tunkiss J \& Galler J R (1996). Malnutrition and reactivity to drugs acting in the central nervous system. Neuroscience and Biobehavioral Reviews, 20: 389402.

6. Rocha JBT, Santos JET, Rocha LK \& Kleinpaul ER (1997). Undernutrition during suckling changes the sensitivity to haloperidol and chlorpromazine in two behavioral measures in weaning rats. Pharmacology and Toxicology, 81: 114-123.

7. Viana GSB, Figueiredo RMO \& Bruno J A (1997). Effects of protein-energy malnutrition on muscarinic receptor density and acetylcholinesterase activity in rat brain. Annals of Nutrition and Metabolism, 41: 52-59.

8. Crnic LS (1976). The effects of infantile undernutrition on adult learning in the rat: Methodological and design problems. Psychological Bulletin, 83: 715-728.

9. Lynch A (1976). Postnatal undernutrition: An alternative method. Developmental Psychobiology, 9: 39-48.

10. Plaut SM (1971). Studies of undemutrition in the young rat: Methodological considerations. Developmental Psychobiology, 3: 157-167.

11. Smart J L \& Preece J (1973). Maternal behavior of undernourished mother rats. Animal Behaviour, 21: 613-619.
12. Wiener SG, Fitzpatrick KM, Levin R, Smotherman WP \& Levine S (1977). Alterations in the maternal behavior of rats rearing malnourished offspring. Developmental Psychobiology, 10: 243-254.

13. Crnic LS (1980). Models of infantile undernutrition in rats: Effects on maternal behavior. Developmental Psychobiology, 13: 615-628.

14. Fleischer SF \& Turkewitz G (1981). Alterations of maternal behaviors of female rats caring for malnourished pups. Developmental Psychobiology, 14: 383-388.

15. Tonkiss J , Smart J L \& Massey RF (1987). Effects of early life undemutrition in artificially reared rats. 2 . Subsequent behavior. Physiology and Behavior, 41: 555-562.

16. Smart J L, Billing AE, Duggan J P \& Massey RF (1989). Effects of early life undernutrition in artificially reared rats: 3 . Further studies of growth and behavior. Physiology and Behavior, 45: 1153-1160.

17. Massaro TF, Levitsky DA \& Barnes RH (1974). Protein malnutrition in the rat: Its effects on maternal behavior and pup development. Developmental Psychobiology, 7: 551-561.

18. Crnic LS (1976). Maternal behavior in the undernourished rat (Rattus norvegicus). Physiology and Behavior, 16: 677-680.

19. Frankova S (1971). Relationship between nutrition during lactation and maternal behavior of rats. Activitas Nervosa Superior, 13: 1-8.

20. Ruil TR, Carvalho AF, Almeida PS, DeOliveira LM \& Almeida SS (1999). Ethological analysis of mother-pup interaction and other behavioral reactions in rats: effects of malnutrition and tactile stimulation of the pups. Brazilian J ournal of Medical and Biological Research, 32: 975-983.

21. Frankova S (1974). Effects of protein deficiency in early life and during lactation on maternal behavior. Baroda J ournal of $\mathrm{Nu}$ trition, 1: 21-28.

22. Frankova S (1979). Behavioral consequences of early malnutrition and environmental stimuli. In: Levitsky DA (Editor), Malnutrition, Environment, and Behavior: New Perspectives. Cornell University Press, Ithaca, NA, USA.

23. Smart J L (1976). Maternal behavior of undernourished mother rats towards well fed and underfed young. Physiology and Behavior, 16: 147-149.

24. Mello CF, Rotta FT, Souza DO \& Rocha
J BT (1989). Undernutrition during suckling and latent learning ability of rehabilitated adult male rats. Behavioral and Neural Biology, 52: 39-50.

25. Leon M, Croskerry PG \& Smith GK (1978). Thermal control of mother-young contacts in rats. Physiology and Behavior, 21: 793811.

26. Stern J M \& Lonstein J S (1996). Nursing behavior in rats is impaired in a small nest box and with hyperthermic pups. Developmental Psychobiology, 29: 101-122.

27. Stern J M (1990). Multisensory regulation of maternal behavior and masculine sexual behavior: a revised view. Neuroscience and Biobehavioral Reviews, 14: 183200.

28. Stern J M \& Kolunie J M (1989). Perioral anesthesia disrupts maternal behavior during early lactation in Long-Evans rats. Behavioral and Neural Biology, 52: 20-38.

29. Stern J M \& Kolunie J M (1991). Trigeminal lesions and maternal behavior in Norway rats. 1. Effects of cutaneous rostral snout degeneration on maintenance of nurturance and maternal aggression. Behavioral Neuroscience, 105: 984-997.

30. Giordano AL, J ohnson AE \& Rosenblatt J S (1990). Haloperidol-induced disruption of retrieval behavior and reversal with apomorphine in lactating rats. Physiology and Behavior, 48: 211-214.

31. Mann PE, Pasternak GW \& Bridges RS (1990) Mu 1 opioid receptor involvement in maternal behavior. Physiology and Behavior, 47: 133-138.

32. Ness JW \& Franchina JJ (1990). Effects of prenatal alcohol exposure on rat pups' ability to elicit retrieval behavior from dams. Developmental Psychobiology, 23: 85-99.

33. Sahakari SD, Abraham ME \& Mascarenhas J F (1989). Effect of stress on maternal behavior. Indian J ournal of Physiology and Pharmacology, 33: 93-96.

34. White NR, Adox R, Reddy A \& Barfield RJ (1992). Regulation of maternal behavior by broadband pup vocalizations. Behavioral and Neural Biology, 58: 131-137.

35. Wiener SG, Smotherman WP \& Levine S (1976). Influence of maternal malnutrition on pituitary-adrenal responsiveness to offspring. Physiology and Behavior, 17: 897901. 